\title{
Comprehensive overview of extracellular vesicle proteomics in meningioma: future strategy
}

\author{
Rashmi Rana ${ }^{1}\left[\right.$. Swati Sharma ${ }^{1} \cdot$ Nirmal Kumar Ganguly $^{1}$
}

Received: 11 May 2021 / Accepted: 15 September 2021 / Published online: 23 October 2021

(c) The Author(s), under exclusive licence to Springer Nature B.V. 2021

\begin{abstract}
Background Meningioma arising from meninges is one among the various types of brain tumors. Others are, astrocytomas originating from astrocyte, oligodendrogliomas originating from oligodendrocyte, Ependymomas originating from ependymal cells and medulloblastomas originating from neurons. Current knowledge of molecular biology, genetics and epigenetics of meningioma is not sufficient. Therefore, In depth understanding of the mechanism of meningioma formation and progression is needed for its treatment and management. Grade I Grade I meningiomas are majorly classified as grade I, grade II and grade III. Meningioma can be indolent, slow growing or can be invasive and metastatic which can recurre. Grade I meningioma can be removed by surgery in comparison to invasive meningioma which may recurre with high propensity. This property of recurrence is responsible for high morbidity and mortality. Meningioma are majorly classified into three classes namely grade I, grade II, grade III. Protein biomarkers are considered as promising candidates for the diagnosis of meningioma. Study Various studies done on differential expression of proteins have shown increased expression of EGFR, NEK9, EPS812, CKAP4, SET and STAT2, in all the three grades of meningioma. Additionally, some proteins like HK2 are overexpressed in grade II and grade III meningioma than in grade I meningioma. Protein Markers, found on extracellular vesicles of different grades of meningioma can serve the same purpose. A test done on a sample of any kind of body fluid like blood, tear, saliva, urine etc. for recognizing the circulating cancer cells or DNA and extracellular vesicles released from them to help detecting the early stage of cancer is known as liquid biopsy. Solid biopsy has several limitations as compared to liquid biopsy. This is because the samples can be easily collected and studied in case of liquid biopsy. Exosomes are related with liquid biopsy and hence provide platform for better diagnosis, prognosis and treatment of any type of cancer including meningioma. Exosomal tetraspanin are important example of exosomal biomarkers. The tetraspanin network is a molecular scaffold which connects various proteins for signal transduction.

Conclusion This study tells about the utility of proper knowledge of extracellular vesicle proteins and their profiles in different grades, which can help in better understanding of pathogenesis, diagnosis, prognosis and treatment of meningioma. In Addition to use of these proteins as biomarkers, role of exosomes in currently available therapeutic approaches has been discussed.
\end{abstract}

Keywords Proteomics $\cdot$ Extracellular vesicles $\cdot$ Exosomes biomarkers $\cdot$ Meningioma $\cdot$ Therapeutics $\cdot$ Drug delivery vehicles $\cdot$ Vaccines

\section{Introduction}

Meningiomas are common central nervous system (CNS) tumors. They arise from the meninges, the outer covering of the brain and spinal cord. Based on the morphologic characteristics, it has been divided into three grades by WHO.

Rashmi Rana

rashmi.rana@sgrh.com; rana_aiims@yahoo.co.in

1 Department of Research, Sir Ganga Ram Hospital, New Delhi 110060, India
Grade Imeningiomas, Grade II meningiomas, Grade III meningiomas. Grade I shows mitosis of $<4 / 10$ high power field (HPF). Grade II meningiomas differ from grade I in having increased mitosis i.e. 4-19/10 HPF and in having three of the following five features 1 . Hypercellularity 2. Smaller sized cells with high nuclear/cytoplasm ratio, 3 . Their nucleoli are prominent 4 . Patterenless sheet like growth 5 . Foci of "spontaneous" or "geographic" necrosis. Grade III meningioma is characterized by even higher mitotic activity $(\geq 20 / 10$ HPF) and their cytology is similar to carcinoma, sarcoma, and melanoma. There are nine histologic subtypes of Grade 
I meningioma namely meningiothelial, fibrous, microcystic, transitional, psammomatous, secretary, lympho plasmcyte rich, angiomatous, metastatic [1]. Two subtypes of grade II meningioma are clear cell and chordoid subtypes. Like Grade II meningioma, Grade III meningioma has two subtypes namely rhabdoid and papillary subtypes [2]. Grade III show high tendency of recurrence and its prognosis is more difficult compared to the grade IIand grade I tumors. The meninges comprise of dura mater, arachnoid and pia mater. Meningioma name has been derived, because of its production from meninges [3]. Meningioma is considered to be originated from arachnoid cap cells ([4]. The origin and progression of grade II and grade III meningioma are still unclear. However, origin of high grade tumors from low grade is well studied in some types of cancers like colorectal cancers and glioblastomas [5].

When it comes to molecular alterations in meningioma, nearly $50 \%$ irregularly spread meningioma contain mutations in Neurofibromatosis 2 (NF2, Merlin) gene [6, 7]. On the other hand, rest $50 \%$ of meningioma contain non NF2 mutations including genes such as TRF7, KLF4, SMO, PIK3CA, POLR2A, PRKAR1A, AKT1 and AKT3 [8]. Even after having advancements in diagnosis and treatment of meningioma, there is not much improvement in controlling the disease. Identification of biomarkers for improved and early diagnosis is a major challenge in the management of meningioma. Proteins are promising, very suitable markers as they are the ultimate functional product of the genome and responsible for biology and behavior of tumor cells. By using antibody based detection methods, they can directly be detected and measured in clinical samples. According to recent reports, protein expression profiling of various types of tumor tissues or the blood samples is providing molecular level knowledge of pathogenesis of cancer and multiple protein biomarkers for various applications. Proteomics technology makes it possible to quantitatively investigate numerous proteins and allows their differential expression profiling at once.

Extracellular vesicles (EVs) are membranous structures secreted by cells into the extracellular space. These are found circulating in biofluids like milk [9], urine [10], blood [11], ascites, saliva etc. [12]. EVs can be of different types such as microvesicles, nanovesicles, exosomes, apoptotic bodies, and are seem to play diverse roles in our body. Among these, exosomes and microvesicles are the most recognized names in this field. EVs can present antigens to immune effector cells, they have the capacity to transport biomolecules including proteins, nucleic acids, lipids and carbohydrates from donor cell to recipient cell. In this way, it is involved in cell to cell communications. These EVs are secreted by all types of cells including immune cells and tumor cells. EVs produced by tumor cells contain molecular effectors of many cancer related processes like growth, invasion, drug resistance, angiogenesis, and coagulopathy. Recently, extracellular vesicles have been explored as a source of tumor specific biomarkers (proteins, nucleic acids, carbohydrates and lipids etc.) which can be used in diagnosis and treatment of different types of tumors including meningioma. Proteomic studies will reveal use of EVs as protein biomarker source which help in diagnosis of disease. EVs may be used in delivering drugs to the target site in our body. EVs can also be used as cell free vaccines due to their property of inducing immunogenicity and their ability to reflect the tumor cells. In this review, we will discuss the epidemiology, treatment strategies and pathways with special emphasis on a novel therapeutic approach based on extracellular vesicles as source of biomarkers. Herein, their use in future management of meningioma were also discussed.

\section{Epidemiology of meningioma}

Globally, Incidence of intracranial meningioma is $10-15 \%$ of all intracranial tumors.it is one of the most common primary intracranial tumor. In India its occurrence varies from 11.6 to $21 \%$ [13]. Overall incidence of meningioma was 8.3 per 100,000 people in USA in year 2010-2014 [14]. Meningioma incidence is dependent on age. It increases from 0.14 per 100,000 in children ( $0-19$ year age group) to 37.75 per 100,000 in the adults/ old age (75-84 year age group). Data revealed increased incidence of meningioma in AfricanAmerican compared with Caucasians. Also, female showed high incidence of meningioma than males in the ratio of 2.27:1. Higher incidence in females correlates with higher level of endogenous and exogenous sex hormones. Pregnant females have more incidence than normal female and the ratio is approximately $3: 1$ [15]. Because of this estrogen and progesterone are considered to have link with this disease. $81.1 \%$ are grade I tumors grade I, $16.9 \%$ grade II tumors and $1.7 \%$ are grade III tumors [14]. The risk factors of meningioma can be intrinsic or extrinsic. Intrinsic factors include sex, allergy and autoimmune disease, genetic polymorphism while ionizing radiations, cigarette smoking, use of cellular phones, pesticides, nutrition, nitroso compounds and hormonal factors come under extrinsic factor category. The most common source of exposure of ionization radiation is dental radiographic examination. The most common hereditary cause of meningioma is mutation in gene neurofibromatosis type 2(NF2) which is an autosomal dominant condition. 


\section{Treatment strategy (surgery, radiation therapy, chemotherapy)}

In case of asymptomatic patients, acceptable strategy used for routine observation and surveillance is imaging. On the other hand, for symptology causing tumors maximal safe surgical resection is the best strategy. Surgical excision depends on various limiting factors like tumor location, involvement of nearby dural venus sinuses, arteries, cranial nerves, brain invasion into eloquent tissue. All these factors in combination decide to what extent the surgery should be done. Convexity meningiomas are easy to approach and resects but it accounts for one sixth of meningioma. Next come parasaggital tumors which are more complex to resect as they generally involve sagittal sinus. The portion within the sinus is not resected due to high risk of air embolism, high volume blood loss or acute postoperative sinus thrombosis. Tumors at base of skull including sphenoid, olfactory groove, tubercullum sella, cerebellospontine angle or petroclival region need more advanced endoscopic techniques [16]. In radiation therapy, tumor cells are irradiated with high energy beams to damage the DNA of abnormal cells. These can be of different types like External Beam Radiation Therapy (EBRT), Stereotactic Radiation Surgery (SRS), brachytherapy, proton beam therapy, intensity modulated radiation therapy (IMRT) etc. Grade I tumors are irradiated to a dose of approximately $50 \mathrm{~Gy}$, while grade II-III meningioma are treated to approximately 60 Gy with daily fractions over 5-6 weeks using EBRT. Single fraction SRS is typically limited to tumors $<30 \mathrm{~mm}$ diameter and for tumors which are not directly adjacent or compressing radiation sensitive structures like optic chiasm. Multifraction SRS can be used for large tumors. Brachytherapy, proton beam therapy, intensity modulated radiation therapy are relatively advanced and use other type of radiation source.

Chemotherapy is not generally used to treat meningioma and there are only few reports which suggest it as a good treatment option for this disease. The cytotoxic drugs used in chemotherapy are not justifiable for long treatments. Under certain conditions like the inoperable cases, chemotherapy may be used. Chemotherapy works by destroying abnormal cancerous cells which divide at a very quick rate. Since meningioma is slow growing many chemotherapy medications do not give the desired effect. Traditional chemotherapy is effective for treatment of high grade meningioma which reproduces quickly than the grade I tumors. However, the percentage of high grade tumors is much lesser.

\section{Proteomic profiling of meningioma for discovery of biomarkers and possible drug targets}

The exact knowledge of pathogenesis and the molecular basis of tumorigenesis can be known by comparative tissue/blood/cell line proteomic profiling of meningioma. Some such studies on meningioma have been summarized in (Table 1).

All these proteins which showed differential expression were found to be connected with meningioma in one or the

Table 1 Protein expression profiles of meningioma as shown by various studies

\begin{tabular}{|c|c|c|c|}
\hline Sample used in the study & Proteomic techniques or approach used & Important proteins identified or validated & References \\
\hline Meningioma tissue & 2DE, MS, Western blot & $\begin{array}{l}\text { Galectin 3, vimentin, endoplasmin (down regu- } \\
\text { lated) } 40 \mathrm{~S} \text { ribosom protein } \mathrm{S} 12 \text {, glutathione } \\
\text { S-transferase P, Hypoxia up regulated protein } 1\end{array}$ & {$[17]$} \\
\hline Meningioma tissue & 2DE, MS, Western blot, Immunohistochemistry & $\begin{array}{l}\text { Apolipoprotein E, lpha } 1 \text { antitrypsin serum albu- } \\
\text { min, Apolipoprotein A1 }\end{array}$ & {$[18]$} \\
\hline Meningioma tissue & iTRAQ labelling, LC-MS/MS, ELISA,ROC & $\begin{array}{l}\text { Gelsolin, galctin tumor protein D54,3 neuromodu- } \\
\text { lin. aapolipoprotein A-I, complement C3, HPX, } \\
\text { alpha } 2 \text { macroglobulin, alpha1 antitrypsin, serum } \\
\text { amyloid A1protein pigmnt epithelium deived fac- } \\
\text { tor, protein S100-A9,Titin ataxin } 7\end{array}$ & [19] \\
\hline Meningioma tissue & LC-MS/MS, western blot, Immunohistochemistry & $\begin{array}{l}\text { EGFR, NEK9, EPS8L2, CKAP4 SET and } \\
\text { STATE2, PXN, TRIP6, S100-A10, SF2/ASF, } \\
\text { ATOX1 }\end{array}$ & {$[20]$} \\
\hline Blood sample & $\begin{array}{l}\text { 2D-DIGE, MADI-TOF/TOF MS, iTRAQ based } \\
\text { and label free LC/MS-MS, western blot, ELISA, } \\
\text { ROC }\end{array}$ & $\begin{array}{l}\text { Hemopexin, serum albumin, heptoglobin, alpha } \\
2 \text { macroglobin, apolipoprotein A-I and sero } \\
\text { transferrin }\end{array}$ & {$[21]$} \\
\hline Meningioma tissue & MS,SRM Assay & $\begin{array}{l}\text { FMNL2, ITGAM, MRC2, SELEN BP1, NDRG1, } \\
\text { MAPK3, EZR, MAP4, ILK, VIM AHNAK, } \\
\text { CLIC1, ESBL2, ANXA2, CKAP4 }\end{array}$ & {$[22]$} \\
\hline Meningioma cell line & 1C-MS/MS & Minichromosome maintenance (MCM) proteins & [23] \\
\hline
\end{tabular}


other way thus, affecting the occurrence of different grades of meningioma in human body. In silico functional analysis of identified differentially expressed proteins showed their involvement in modulating diverse essential signal transduction pathways like integrin signaling, Wnt signaling, FGF (Fibroblast growth factor) signaling, Ras signaling, EGF (epidermal growth factor) signaling, ubiquitin proteasome signaling in meningioma. Human malignancies are associated with abnormal activation or invariable alterations of signaling pathways mainly affecting the cell proliferation or cell cycle, apoptosis, angiogenesis etc. Previously identified potential molecular targets for treatment of meningioma include growth factor receptors EGFR (Epidermal growth factor receptor), VEGFR (vascular epithelial growth factor receptor) and PDGFR (platelet derived growth factor receptor) along with their signaling pathway activation, but pharmaceutical targeting has given mixed results. EGFR inhibitors erlonitib and gefitinib when used as treatment options yielded non-significant results whilst VEGFR and PDGFR inhibitor sunitinib showed some effectiveness but was found to be toxic. Therefore, in order to develop novel therapeutic strategies for meningioma, it is important to identify the abnormally activated pathways and associated molecular new protein targets and biomarkers.

\section{Major signaling pathways involved in meningioma}

\section{Growth factors and chemokines}

Numerous growth factors have been found to be associated with meningioma tumorigenesis including EGF, transforming growth factor $\alpha$ (TGF $\alpha$ ), fibroblast growth factor(FGF) and insulin like growth factor, platelet-derived growth factor$\beta$ (PDGF- $\beta$ )TGF- $\beta$,Stromal cell derived factor 1 (SDF1) bone morphogenetic proteins(BMPs) HER2, somtostatin etc.

\section{The Ras/MAPK pathway}

EGF and PDGF bind to their respective receptors inducing auto phosphorylation of tyrosine kinases on the cytoplasmic side of the receptor. These residues then bind to grb2 and sos proteins which brings them closure to plasma membrane. Ras proteins get activated. Ras are small GTPases involved in signal transduction inside the cell that further activates downstream components like Raf, MEK-1 and ERK causing phosphorylation of various transcription factors. It has been reported that in meningioma cell culture. MEK 1 inhibitors show less MAPK activity and hence less inhibition associated with it [24]. This pathway is aberrantly activated in meningioma affecting growth, differentiation and apoptosis. Activity of many meningioma growth factors mediated by signal pathways. Constitutive activation of MAPK pathway has been seen in grade I grade I meningioma. Marwin et al. showed that a MAPK inhibitor PD98059 diminished cell growth and induced apoptosis in malignant meningioma [25].

\section{PI3K-Akt-mTOR C1 pathway}

EGF and PDGF bind to their respective receptors leading to stimulation of catalytic unit of receptor which is present on cytoplasmic side of the receptor. This autophosphorylates and activates nearby adaptor proteins inducing stimulation of PI3K via PI10 subunit. phosphatidylinositol 4-5 bisphosphate (PIP2) is then catalyzed to PIP 3, 4, 5-tris phosphate (PIP3)with the help of PI3K. This reaction is regulated and inhibited by PTEN. PIP3 then activates Akt protein with the help of mTORC2. Akt initiates several downstream cascades including activation of mTOR. mTOR is a serine/threonine kinase and a catalyst responsible for forming mTORC1 [26] which regulates cell growth and proliferation. Inhibitors of mTOR have been found to be effective in large number of tumors like glioblastoma multiforme. Marwin et al. reported increased expression of phosphorylated Akt in grade III and grade II meningiomas. Also, an Akt inhibitor namely Wortmannn reduced growth and survival of malignant meningioma [25].

\section{The PLC $-\gamma 1-P K C$ pathway}

PLC $-\gamma 1$-PKC pathway is characterized by, cross activation of MAPK as well as PI3K Pathways. MAPK and PI3K pathways are simultaneously activated by the mediators of the pathway [27]. PDGFR and EGFR phosphorylate/activate phospholipase $\mathrm{C} \gamma 1$ that leads to the formation of inositol 1, 4, 5 triphosphate (IP3) and 1, 2 diacylglycerol (1,2 DAG) from phosphatidylinositol 4, 5 diacyl glycerol. IP3 and 1,2 DAG are second messengers.1, 2 DAG stimulates protein kinase $\mathrm{C}$ (PKC), the Raf-MEK1-MAPK/ERK and PI3K-Akt pathways. PKC activates c-fos and c-jun inside the nucleus thus causing cell proliferation and inhibition of apoptosis. Previously, it has been studied that their exist association between PLC $-\gamma 1$ and EGFR in meningioma. When EGFR-Kinase gets activated it leads to phosphorylation of PLC $-\gamma 1$ and a $78 \%$-increase in catalytic activity. Therefore, PGFR and EGFR on binding to tyrosine kinases on meningioma that activates PLC- $\gamma 1$-PKC Pathway, which is one among the various mechanism for promoting meningioma cell growth [28].

\section{NOTCH pathway}

Notch 1-4 proteins are transmembrane proteins which are involved in intracellular communications. Transmembrane 
protein binds to the ligands and proteolytically cleave intracellular domain of notch [29]. This intracellular domain enters the nucleus and causes activation of hairy/enhancer of split family of transcription factor. Genes controlled by notch pathway, function during embryonic development and later during the adult stage. Notch signaling pathway plays role in tumorigenesis. The role of notch signaling pathway is different for different type of cancer. Gene expression analysis have shown link between notch pathway and meningioma. HES1 upregulation was found in all grades of meningioma and correlated with upregulation of notch1, notch2, jagged ligand. HES1 activity is modulated by transducing-like enhancer of the split family of corepressors and upregulated in malignant meningioma that suggest that TLE3/HES1 is linked to more aggressive forms of meningioma [30].

\section{HEDGEHOG pathway}

Binding of Hh to PTCH causes suppression of transmembrane protein (SMO). On SMO activation a signaling cascade is initiated which leads to activation of GL1 transcription factors [31]. This family consists of three members GL1, GLII and GLIII. GLI and GLII are growth activators and GLIII is a growth repressor. These transcription factors affect cell growth, proliferation, angiogenesis, stem cell homeostasis and matrix remodeling. In this way, hedgehog pathway play role in tumorogenesis [31]. In same study, mRNA expressions of $32 \mathrm{Hh}$ pathway associated genes were examined. In all tumor grades, 16 genes were found to be amplified and 7 genes were found to be downregulated.

\section{Wnt pathway}

Wnt signaling pathway is involved in apoptosis and is important in development of meningioma. Wnt pathway is activated when frizzled protein extracellularly binds to Wnt. It acts synergistically to LRP5/6 leading to binding of GSK $\beta$, DVL, CK1, AXIN to the plasma membrane. This dephosphorylates $\beta$ catenin thus maintaining high level of $\beta$ catenin in the cytoplasm. Available Catenin bind to transcription factors which results in increased transcription of apoptotic genes. APC remains free in the cytoplasm during dephosphorylation [32]. When Wnt pathway is inactivated, glycogen synthasekinase- $3 \beta$ (GSK $\beta$ ) with the help of complex Axin, CKI, APC phosphorylate $\beta$-catenin. This occurs on replacement of DVL by APC. The complex thus formed on phosphorylating $\beta$ catenin causes degradation of catenin through a proteasome and there is no transcription of apoptotic genes. DVL protein remains in unbounded form in the cytoplasm during inactivation of Wnt pathway. Recent gene expression studies have shown role of Wnt pathway in activating meningioma. Loss of APC (adenomatous polyposis coli $(A P C)$ gene, a tumor suppressor gene has been seen in grade I meningioma. Modulators of Wnt pathway were found deficient in one-third of meningioma.

\section{TGF $\beta$ SMADS signaling pathway}

The TGF beta superfamily of ligands include: Bone morphogenetic proteins (BMPs), Activin, TGF $\beta$ 's, Growth and differentiation factors (GDFs), Anti-müllerian hormone (AMH) and Nodal. These help in growth and differentiation during embryogenesis. The TGF beta family include: TGF $\beta 1$, TGF $\beta 2$, and TGF $\beta 3$. TGF $\beta$ 's differ from other TGF beta superfamily members in that the TGF beta family induces apoptosis along with growth and differentiation. These TGFs bind to receptor type II and later phosphorylates receptor type I. Receptor I then phosphorylates receptor regulated SMAD (R SMAD). R SMAD now can bind to CO SMAD, SMAD 4. Both the receptor regulated R SMAD and CO SMAD form complex and move towards nucleus. After entering the nucleus they act as transcription factors and regulate the expression of target genes. These inhibitory growth factors /receptors and their signaling pathways also affect meningioma growth. For example, TGF $\beta$ is upregulated in the leptomeninges. Proliferation of WHO Grade I meningioma cells and leptomeningeal cells is inhibited by TGF beta I. On adding TGF beta neutralizing antibodies to CSF, there is increase in mitogenic effects on meningioma cells [33]. The role of TGF beta in meningioma pathogenesis is still to be established (Fig. 1).

$\mathrm{Rb} / \mathrm{p} 53$ pathway, Phospholipase A2 arachidonic acid cyclooxygenase signaling pathway are also dysregulated in case of meningioma [34].

\section{Other important signaling pathways}

\section{Coagulation pathway}

Coagulation of blood is also termed as blood clotting. Coagulation process involves four steps (1) constriction of blood vessel (2) temporary platelet plug formation (3) activation of coagulation cascade (4) formation of fibrin plug, the final clot. Cancer damages the healthy tissue of the body. To resist such ill effects, blood clotting takes place. Blood clotting prevents excessive loss of blood and also give time for tissue to repair, therefore, cancer patients have high risk of blood clots and clotting disorders. It is accompanied with SERPINA1 mediated inhibition of degradation of extracellular matrix by serine proteases. This serine protease inhibitor has been seen to be associated with various types of cancers such as lung, colorectal and gastric carcinoma [35]. It has also been reported to have link with meningioma as the expression of SERPINA increases with increase in tumor grades [36]. SERPINA1 thus can acts as potent prognostic marker. 


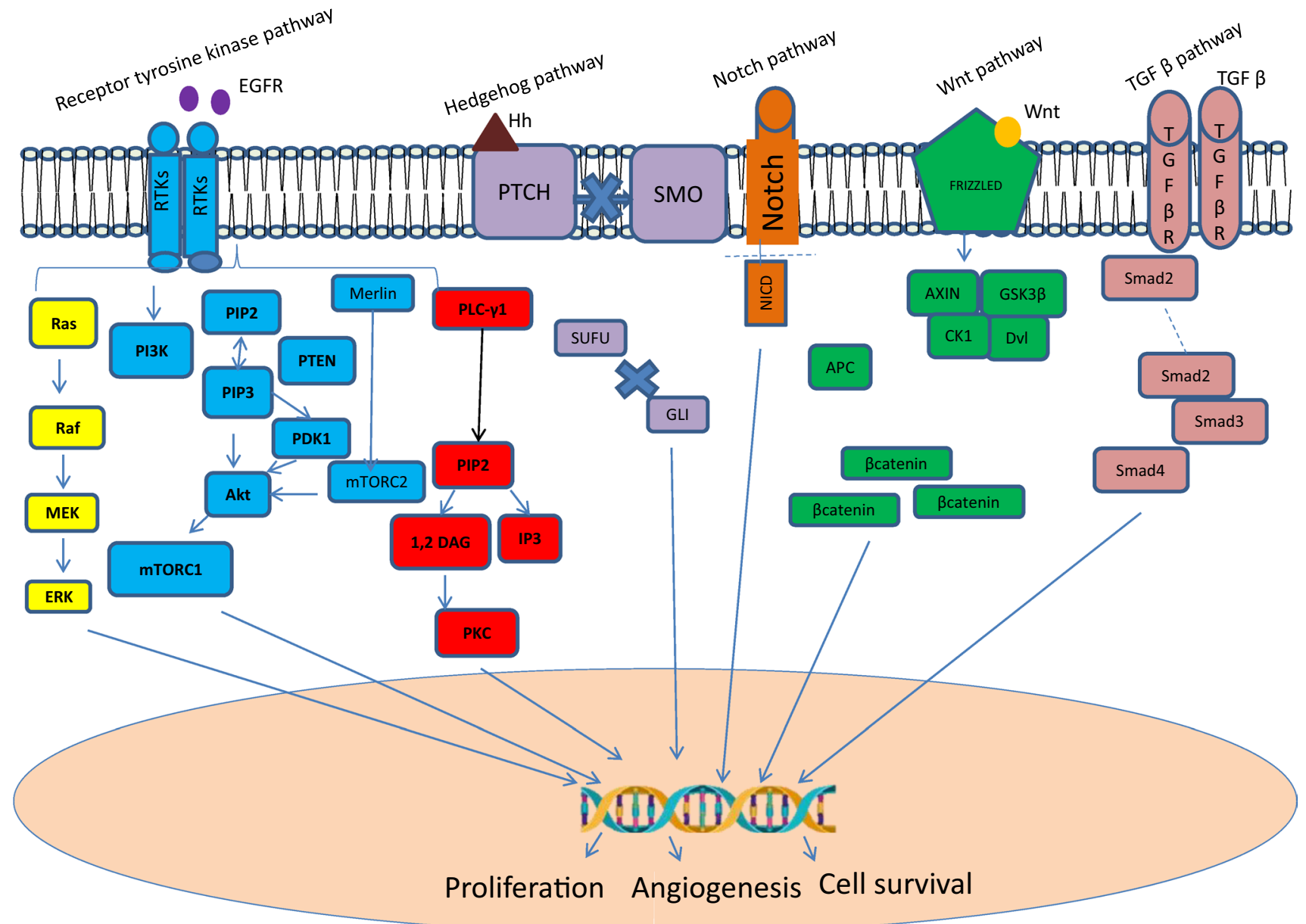

Fig. 1 Signaling pathways: receptor tyrosine kinase, Hedgehog, Notch, WNT and TGF $\beta$ pathway in meningioma

\section{Complement pathway}

Complement pathway plays a role in immune system. This pathway has been seen to help cells, proliferate and regenerate. Recently, activation of complement pathway in meningioma has been studied. Exact mechanism of how complement system functions to develop a cancer is still not clear but it is postulated that it is involved in constant cellular proliferation, resistance to apoptosis, escape from immune system, dysregulation of mitogenic signaling pathway. Enhancement of complement pathway member C3 level was observed along the grades of meningioma representing suitability in its use as a prognostic marker [36]. Overexpression of C3 and C5b-9 complex was also observed in glioblastoma multiforme [37].

\section{Lipid metabolism pathway}

Fatty acids or lipids are critical for cell growth and development. It is a structural component of the cells, provides energy to them and act as signaling molecules. Tumor cell formation and increase in fatty acids synthesis proceed side by side. ALB and APOAI proteins associated with lipid metabolism and lipid remodeling were found to be upregulated in cancer patients and serve as diagnostic and prognostic biomarkers, especially in case of brain tumor. Study by Abbritti et al. showed that there was overexpression of ALB and APOAI along the grades of meningioma proving its involvement in meningioma progression [36]. Apolipoproteins (APOAI) are polypeptides which regulate efflux and transport of cholesterol from peripheral tissues to the liver. According to a study by [38, 39], albumin acts as carrier for APOAI. Both these proteins are implicated to malignant glioma formation.

Overexpression of some other proteins like HPX, HP, APCS and A1BG was also evident but their functioning of these proteins is not known in connection with meningioma.

\section{Integrin signaling pathway}

Cell proliferation and signal transduction are major functions performed by integrin proteins. Integrin alpha $\beta 5$ and 
alpha $\alpha \beta 3$, vasodilator stimulated phosphoprotein, filamin A, collagen $\alpha 3$ chin were established to be upregulated in grade I meningioma [40].

\section{Gonadotropin releasing hormone pathway}

Previous studies on Gonadotropin releasing hormone and its receptor have shown a connection with occurrence of meningioma. Studies showed increased expression of tissue proteins like caveolin, vinculin, SHC binding protein and guanine nucleotide binding protein $\mathrm{G}$ subunit $\alpha$ complement factor $\mathrm{B}, \mathrm{Y}$ box protein, in all grades of meningioma and showed lower expression of proteins like tubulin alpha $-1 \mathrm{C}$ chain and serine/threonine protein phosphatase 2B [41]. Other pathways which get modulated include chemokine and cytokine signaling pathway. chemokine receptor helps in tumor proliferation [42]. Signaling by rho GTPases and EGF receptor signaling pathway again play role in tumor proliferation [43]. Apoptotic signaling pathway, Fibroblast growth factor signaling pathway. Ras pathway and dopamine receptor signaling pathway has also shown role in meningioma pathobiology [44, 45].

\section{Characteristics of meningioma cells and the mechanistic insights}

\section{Tumor suppressor genes and PI3K/Akt/mTOR pathway linked to cell growth and proliferation}

Dysregulation of cyclin, cyclin dependent kinases and their inhibitors affect growth and proliferation of meningioma cells [46]. The cyclin dependent kinase inhibitor $2 \mathrm{~A}$ (CDKN2A) gene encodes cell cycle regulating proteins like p16 and p14 inhibiting tumor cell growth. If these proteins are less expressed they become responsible for the tumor growth. mTOR (mammalian target of rapamycin) controls cell growth, differentiation proliferation and tumorigenesis. mTOR is over-expressed in brain tumor. Phosphoinositide3-kinase and protein kinase B (Akt) pathway regulate mTOR. Phosphoinositide-3-kinase is in turn regulated by many growth factors and their receptors such as epidermal growth factor (EGF) and its receptor (EGFR). According to a study, inhibition of this pathway leads to suppression of abnormal cell proliferation and increased cell death [47].

\section{Cadherin pathway linked to cell invasiveness}

Cell adhesion property goes on decreasing with the transformation of normal cell into cancerous cell. E-cadherin forms complex with $\beta$ catenin thus regulating adhesiveness and stability of cell. MPPs (Matrix metalloproteinases) are zinc dependent endopeptidases that degrade extracellular matrix and tissue reconstruction hence are the cause of increased cell invasiveness. Studies have shown that lower expression of E- cadherin, A kinase anchor protein 12 and loss of density enhanced phosphatase- 1 is responsible for increased cell invasiveness [48].

\section{Vascular endothelial growth factor (VEGF) pathway for angiogenesis}

An important property of malignant cells is that their vasculature is more efficient than the normal cells. Angiogenic factors remain balanced in a normal cell, when this balance is perturbed it leads to interaction of angiogenic factors affecting the biological behavior of meningioma. The most important angiogenic factor is vascular epithelial growth factor which takes part in numerous physiological and pathological pathways related to angiogenesis. Many tumor metabolic processes like glycolysis, angiogenesis, apoptosis, and promotion of tumor growth are regulated by Hypoxia inducible factor $1 \alpha(\mathrm{HIF}-1 \alpha)$. HIF-1 $\alpha$ activates VEGF transcription and stabilizes VEGF and its receptor promoting endothelial cell proliferation and neovascularization. Similarly, HIF3 $\alpha$ upregulates VEGF via JAK/STAT signaling pathway and promotes tumor angiogenesis. According to one study, MMP-9 is upregulated in meningioma and is closely linked to neovascularization and tumor. MMP9 causes degradation of extracellular matrix and thereby creating space and stimulation for angiogenesis. It also stabilizes VEGF and its receptor [49].

\section{Future prospective}

\section{Role of extracellular vesicles}

Extra cellular vesicles are membranous structures secreted by cells including the cells of central nervous system and by malignancies of brain into the extracellular space [50]. EVs can be released constitutively or its formation may be induced by cell stimulation, activation, differentiation, stress, radiation, senescence, oncogenic transformations or different forms of programmed cell death. EVs contain repertoire of proteins, lipids and nucleic acids (mRNA, microRNA, mtDNA, and DNA) [51, 52]. Based on their biogenesis, release pathways, size, content and functions, EVs are classified into four important types. These are exosomes, microvesicles, large oncosomes and apoptotic bodies. Exosomes are small having size, $30-100 \mathrm{~nm}$ in diameter. Microvesicles, ectosomes or microparticles (MPs) are larger than the exosomes having size $100-1000 \mathrm{~nm}$ in diameter. Other vesicles are large oncosomes have diameter greater than $2 \mathrm{~mm}$, which is relatively larger than microvesicles and 
exosomes. Apoptotic bodies are even larger than oncosomes having size of $1-2 \mu \mathrm{m}$ in diameter.

The properties of these different types of extracellular vesicles can be described one by one. exosomes are rich in tetraspanins (CD63, CD81, CD82, CD9) export molecules like RAB27a/b, TSG101, Alix and heat shock proteins (HSP90, HSP70), proteases (ADAM10), integrins, receptor tyrosine kinases, immunomodulation molecules, nucleic acids, bioactive phospholipids etc. [53]. Multivesicular bodies (MVBs) are considered to be originating source of exosomes which are formed through endosomal pathway during membrane recycling process [54]. Microvesicles have flotillin-1 integrins and tetraspanins common to lipid rafts and exosome. Their synthesis depends on acidic, sphingomyelinase, lipid flopasses, ARF6 and other proteins clusters at surface of cells [55]. Oncosomes formation is regulated by actin binding proteins AKT, EGFR and other pathways [56]. Apoptotic bodies contain breakdown elements of cellular mass like nuclear DNA and organelles [57].

Exosomes are the most important type of extracellular vesicles. They play important role in the transfer of functional proteins, lipids, nucleic acid and metabolites from donor cells to recipient cells thus affecting neural maintenance and repair, homeostasis, immunity, hematopoiesis, inflammation, angiogenesis and several other processes [58]. They can be used as biomarkers for diagnosis and prognosis of meningioma. However, there are very less reported studies on this topic and it is a hotspot to be worked on.

\section{Application of exosomes as liquid biopsy in clinical diagnosis and treatment of meningioma}

Use of exosomes as biomarkers in liquid biopsies is a relatively new and enthusiastic field. Liquid biopsy is, detecting the cancer at an early stage of progression, by testing cell free DNA (cfDNA), circulating tumor cells(CTCs) and exosomes circulating tumor DNA (ct DNA), mRNA (messenger RNA), miRNA (microRNA), extracellular vesicles (EVs) released by cancer cells in bodily fluids [59-61].

Exosomes or small extracellular vesicles play vital role in various types of physiological and pathological processes namely cancer, cardiovascular diseases, pregnancy disorders, immune response [62]. Liquid biopsy is better than solid biopsy as it does not require invasive operations and are more precise [63]. Exosomes present many advantages compared to other sources.

- High stability in all body fluids. They contain cargo similar to cell.

- Better accuracy than other markers like carcinoembryonic markers [64].

- They include many specific proteins like CD63, Alix, TSG101 and HSP 70 [65].
- Cup shaped structure highly recognizable [54].

- They present specific cellular surface proteins like their parent cell [66] helpful in predicting organ specific metastasis [67].

- Easily available through isolation methods like ultracentrifugation [68].

\section{Exosomes as biomarkers in early tumor diagnosis}

In order to reduce mortality and increasing the recovery rate of cancer patients and patients with precancerous lesions, early screening and accurate diagnosis is important. Exosomes are quite efficient in distinguishing cancerous and non-cancerous patients. One important example where exosomal proteins act as early diagnostic tool is exosome based EGFR T790M in non-small cell lung cancer (NSCLC) [69]. Similarly, CD151, CD171 and tetraspanin showed great potential for diagnosis of lung cancer [70]. MS (Mass Spectrometry) have made it possible to analyze thousands of proteins from single sample of micro quantity. Study on breast cancer by Chen et al., using MS showed increased expression of 144 exosome phosphorylated proteins among them PKG1, RALGAPA2, TJP2, NFX1 are the more expressed [71]. These tests were done on blood derived exosomes however, urine derived exosomes were also used for testing of urinary system or genitourinary tract related cancers [72]. Another important example is renal cell carcinoma. In this study, 10 selected exosomal proteins were used to distinguish cancer patients from normal individuals [73]. Recently, using latest advanced technologies, different exosomal biomarkers are being identified in various cancers like lung [70], pancreas [74], bladder [75], breast [76], ovarian [77], prostate [78] and melanoma [79]. Proteins which are identified from exosomes include proteins involved in the formation and secretion of exosomes as annexins,SNAREs, Rab GTPases, flotillin, tetraspanins (CD9, CD63, CD81, CD151), Heat shock proteins (HSP 60, HSP70, HSP90), Proteins involved in ESCRTcomplex TSG 101, EpCAM(Epithelial cell adhesion molecules), Alix and MHC molecules.

\section{Exosomes in tumor prognosis prediction}

Studies on lung cancer revealed higher annexin A6 enriched exosomes after cytosolic chemotherapy and found to be linked with metastasis. Annexin 11 [80] and L plastin [81] play important role in metastasis and act as prognostic factor for advanced breast cancer. MS protein profiling studies in prostate cancer showed upregulation of urine derived exosomal proteins ITGA3 and ITGB 1 in metastatic patients against the patients with grade1 tumor and early stage cancer [82]. Exosomal protein PD-L1 act as prognostic marker for head and neck cancer [83] and non-small cell lung cancer. 
[84] Also, serum based exosomal PD-L1 can predict pancreatic ductal carcinoma [85].

\section{Exosomes in tumor treatment response assessment}

Exosomes play role in drug resistance which is one big obstacle for treatment of advanced malignant tumors. Tumor derived exosomes can transfer drug resistance associated molecules to recipient cells promoting signal transduction alterations, antiapoptotic pathway leading to treatment failure. In this way such exosomes can act as biomarkers for cancer treatment [86].

\section{Exosomes as drug delivery vehicles and vaccines for the treatment of meningioma}

Due to the delivering properties of exosomes, these are used to deliver different types of drugs into the affected cells for disease treatment. For this purpose, the drugs loaded into the exosomes can be broadly classified into three types namely Protein drugs, genetic drugs and chemical drugs. Exosomes have been loaded with variety of anticancer drugs (paclitaxel, doxorubicin), cancer gene suppressors (c-Myc siRNA, PLK-1 siRNA, miRNA 134 and miRNA 143 etc.) [87]. Protein drugs mainly include enzymes, cytokines, transmembrane proteins, peptides and cytoskeletal proteins. Proteins drugs are comparatively new and useful in treatment of malignant tumors. Important example is loading of caspase 1 (ICE) INTO AAV serotype 1 vectors to prevent schwnnoma growth [88]. Exosomes can also transport carriers for protein drugs for stabilization and achievement of targeted administration. Survivin inhibits apoptosis protein that is responsible for apoptosis resistance. Survivin-T34A mutant was seen to block survivin, activating caspase induced apoptosis [89]. Other important example include loading of exosome with glycosylphosphatidylinositol (GPI)- anchored PH20 hyaluronidase. Membrane protein treatments are what it's all about. It can penetrate deep into malignancy by eliminating tumour extracellular hyaluronan quickly and permanently. It produces a space between tumour vascular endothelial cells, increasing tumour blood vessel permeability and decreasing tumour growth [90]. In another situation, it was discovered that exosomes containing signal regulatory protein (SIRP) performed better than SIRP -conjugated ferritin nanocage formulations [91]. To date, passive targeting method is most studied targeting method in comparison to active targeting [92]. However, active targeting of exosomes as protein delivery system is more precise and reduces non target tissue and organ damage.

Recently, exosomes have been used as a cell free vaccine for renal cancer cells. It was seen that when dendritic cells were loaded with tumor antigens or tumor exosomes (TEXs) they could induce immunogenicity in mice. Tumor antigen can directly be pulsed with dendritic cells to produce dendritic cell derived exosomes (DEXs) which can process and present antigen like parent dendritic cells. This leads to activation of cytotoxic T cells and killing of tumor cells. Immune cell derived exosomes or dendritic cell derived exosomes (DEXs) can thus be used in vaccine production. In other method, tumor cells are modified genetically or by providing stress and allowed to produce tumor derived exosomes (TEXs) which just like above described DEXs have the efficiency of inducing dendritic cells. These DEXs, this time produced inside the body, can process and present antigen to cytotoxic cells. Tumor cells are killed by activated cytotoxic cells. In this way, TEXs can also be used in vaccine formation. TEXs have bound PD-L1 on their membrane and enriched with protein and nucleic acid mimicing tumor cells in their content and activity. TEXs on transferring this cargo to recipient cells can activate molecular pathways and induce protumor transcriptional changes [93]. These can play dichotomous role as it can induce suppressive or active immune responses. These Immune cell derived exosomes /DEXs and TEXs can be helpful in cancer diagnosis and immunotherapy. Proteomic level study and study by other means have shown that exosomes are important and help in management of meningioma but the study is still in its hypothetical stage [94]. Identification of these immunogenic cancer antigens present on TEXs are vital in cancer vaccine development. Today, different cell free vaccines of exosomes are under trial and are in various phases of development [87]. If they are properly administered they can be used to induce immune response against tumor. Tumor derived exosomes (TEXs) are suitable for this purpose because of biosafety reasons. The role of exosomes in the treatment of meningioma through vaccine development is depicted (Fig. 2).

\section{Proteomic approaches to study extracellular vesicles (exosomes)}

In order to get in depth knowledge of exosomes, proper optimized methods for their isolation, characterization and proteomic analysis need to be searched. Till date, available methods used for obtaining exosomes out of the plasma include ultracentrifugation, immune isolation of exosomes using magnetic microbeads, extraction kit, microfluidics and biosensors. Morphological characterization of EVs and analysis of EVs are done by Transmission electron microscopy (TEM) or atomic force microscopy (AFM). Particle enumeration technique like dynamic light scattering (DLS), nanoparticle tracking analysis (NTA) are also used for EVs analysis. Flow cytometry is used to know the EVs origin and it helps in their identification. FACS uses pattern of light scattered and fluorescence measurements to analyze the 


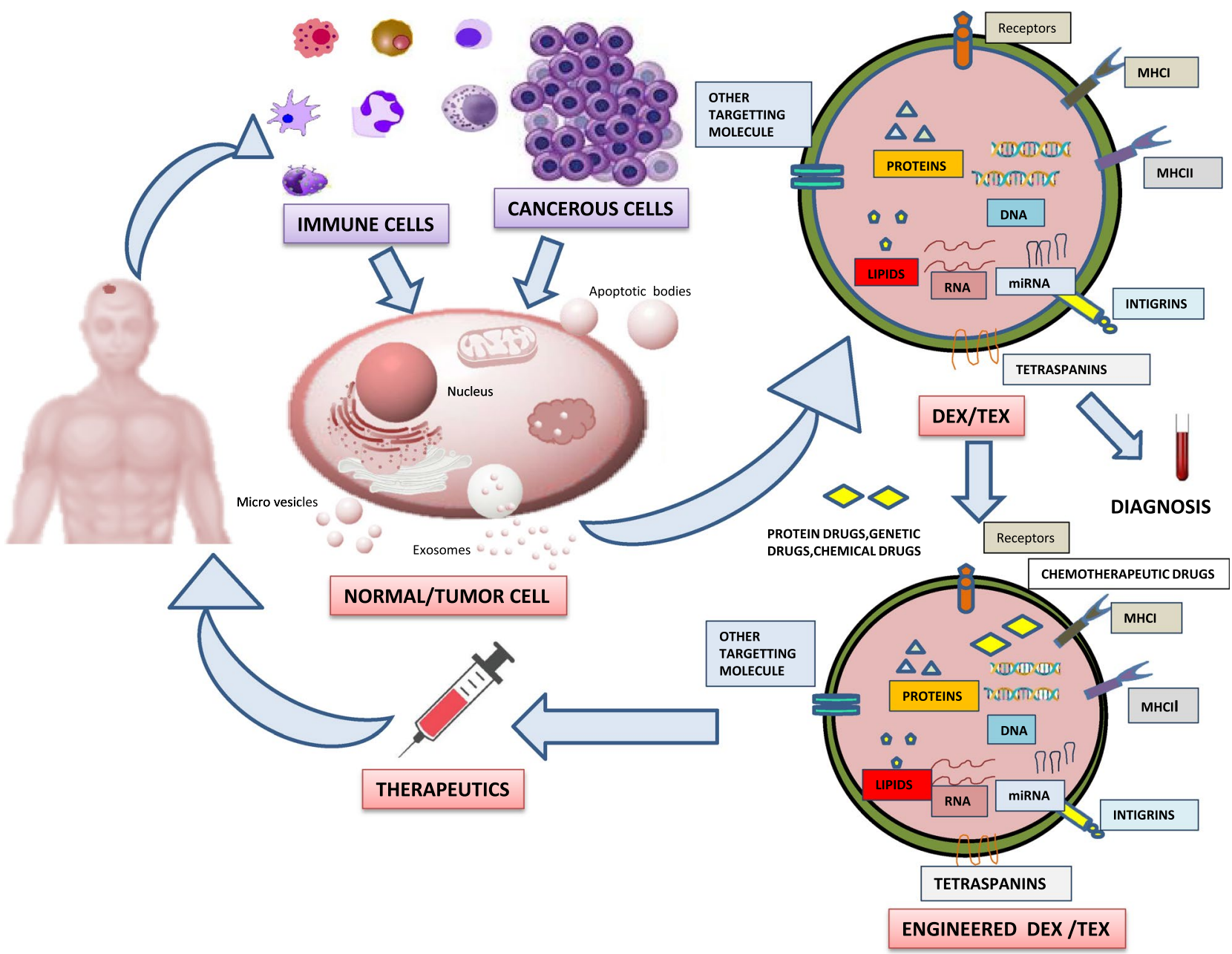

Fig. 2 Engineering of extracellular vesicles (exosomes) for preventing meningioma

exosomes. Exosome protein quantification and identification can be done using LC-MS/MS shown in (Fig. 3).

\section{Conclusion}

Till date, options available for diagnosis, prognosis and treatment of meningioma are not much effective and have harmful side effects. These techniques lack precision, sensitivity and specificity. Apart from this they are costly, and impractical for mass application. Under such tough conditions, Extracellular vesicles (EVs) originating from cells and considered as garbage bags of cells have shown some hope. EVs play important role in cell to cell communication and transfer their cargo of protein, lipid, chemokines, growth factors, nucleic acids, cytokines etc. from donor cells to recipient cells. EVs have been found to be involved in disease progression and pathophysiology. EVs are found responsible for creating and establishing the tumor microenvironment. Studies have shown that EVs population is higher in diseased cells as compared to normal cells. EVs penetrate the disrupted blood brain barrier of meningioma patients and can be observed circulating in blood stream of those patients. Recent development for characterization of extracellular vesicles has promised a better diagnosis, prognosis and treatment of meningioma. Extra cellular vesicles can be characterized using techniques like FACS, NTA and western blotting etc. Similarly, iTRAQ LC MS/MS, SRM, various bioinformatics tools etc. are latest techniques used to study the protein profiling of EVs that provide deeper insight of mechanism and thus, treatment of disease. Certain reports have already shown the involvement of EVs in various types of cancers and they can be helpful for cancer treatment, but still the current knowledge of EVs association with meningioma is scarce. The present review emphasizes on search and identification of new exosome based biomarkers. Even though the EVs are good source of biomarkers in 


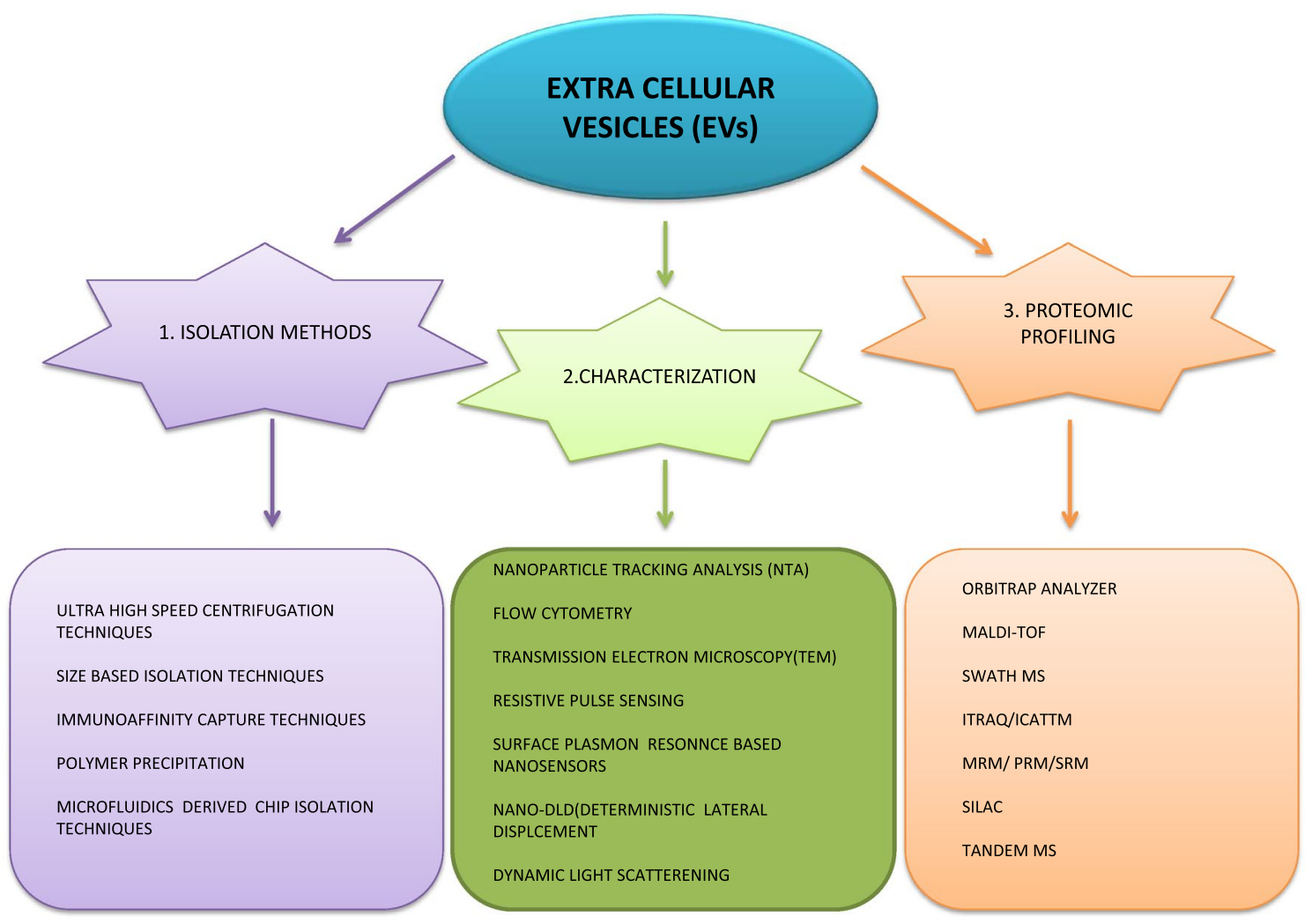

Fig. 3 Isolation, characterization and proteomic profiling of extracellular vesicles (exosomes)

liquid biopsies there are some barriers between the basic research and clinical practice. These barriers need to be removed for better diagnosis, prognosis and treatment of meningioma. First barrier is that there is need of standardization of protocols for isolation of exosomes which provide purity. Second, there is need to identify specific subtypes of EVs. Third, many exosomal biomarkers have been identified still there is urgent requirement to search new biomarkers and validate them all at large scale for their appropriate application. In addition, biological safety of exosomes should also be confirmed. In this review on the pathways involved in meningioma progression, expression pattern of proteins, development of drug delivery vehicles (particularly proteins delivery vehicles) and strategies for use of DEXs and TEXs in meningioma treatment have been described.

Acknowledgements Authors are gratefully acknowledged to Sir Ganga Ram Hospital, Delhi, India for providing necessary support.

Funding None.

\section{Declarations}

Conflict of interest The authors declare that they have no conflict of interest.
Ethical approval This review does not contain any studies with human participants or animals performed by the author.

\section{References}

1. Hale AT, Wang L, Strother MK, Chambless LB (2018) Differentiating meningioma grade by imaging features on magnetic resonance imaging. J Clin Neurosci 48:71-75. https://doi.org/10. 1016/j.jocn.2017.11.013

2. Louis DN, Perry A, Reifenberger G, von Deimling A, FigarellaBranger D, Cavenee WK et al (2016) The 2016 World Health Organization classification of tumors of the central nervous system: a summary. Acta Neuropathol 131:803-820. https://doi.org/ 10.1007/s00401-016-1545-1

3. Al-Rashed M, Foshay K, Abedalthagafi M (2019) Recent advances in meningioma immunogenetics. Front Oncol 9:1472

4. Barthélemy EJ, Sarkiss CA, Lee J, Shrivastava RK (2016) The historical origin ofthe term "meningioma" and the rise of nationalistic neurosurgery. J Neurosurg 125:1283-1290. https://doi.org/ 10.3389/fonc. 2020.565582

5. Al-Mefty O, Kadri PA, Pravdenkova S, Sawyer JR, Stangeby C, Husain M (2004) Malignant progression in meningioma: documentation of a series and analysis of cytogenetic findings. J Neurosurg 101:210-218. https://doi.org/10.3171/jns.2004.101.2.0210

6. Brastianos PK, Horowitz PM, Santagata S, Jones RT, McKenna A, Getz G, Ligon KL, Palescandolo E, Van Hummelen P, Ducar MD, Raza A, Sunkavalli A, Macconaill LE, Stemmer-Rachamimov AO, Louis DN, Hahn WC, Dunn IF, Beroukhim R (2013) 
Genomic sequencing of meningiomas identifies oncogenic SMO and AKT1 mutations. Nat Genet 45:285-289

7. Clark VE, Erson-Omay EZ, Serin A, Yin J, Cotney J, Ozduman K, Avsar T, Li J, Murray PB, Henegariu O, Yilmaz S, Gunel JM, Carrion-Grant G, Yilmaz B, Grady C, Tanrikulu B, Bakircioglu M, Kaymakcalan H, Caglayan AO, Sencar L, Ceyhun E, Atik AF, Bayri Y, Bai H, Kolb LE, Hebert RM, Omay SB, MishraGorur K, Choi M, Overton JD, Holland EC, Mane S, State MW, Bilguvar K, Baehring JM, Gutin PH, Piepmeier JM, Vortmeyer A, Brennan CW, Pamir MN, Kilic T, Lifton RP, Noonan JP, Yasuno K, Gunel M (2013) Genomic analysis of non-NF2 meningiomas reveals mutations in TRAF7, KLF4, AKT1, and SMO. Science 339:1077-1080. https://doi.org/10.1126/science.1233009

8. Clark VE, Harmanci AS, Bai H, Youngblood MW, Lee TI, Baranoski JF, Ercan-Sencicek AG, Abraham BJ, Weintraub AS, Hnisz D, Simon M, Krischek B, Erson-Omay EZ, Henegariu O, CarrionGrant G, Mishra-Gorur K, Duran D, Goldmann JE, Schramm J, Goldbrunner R, Piepmeier JM, Vortmeyer AO, Gunel JM, Bilguvar K, Yasuno K, Young RA, Gunel M (2016) Recurrent somatic mutations in POLR2A define a distinct subset of meningiomas. Nat Genet 48:1253-1259

9. Naslund TI, Paquin-Proulx D, Paredes PT, Vallhov H, Sandberg JK, Gabrielsson S (2014) Exosomes from breast milk inhibit HIV-1 infection of dendritic cells and subsequent viral transfer to CD4+ T cells. AIDS 28:171-180. https://doi.org/10.1097/QAD. 0000000000000159

10. Alvarez S, Suazo C, Boltansky A, Ursu M, Carvajal D, Innocenti $\mathrm{G}$ et al (2013) Urinary exosomes as a source of kidney dysfunction biomarker in renal transplantation. Transpl Proc 45:3719-3723. https://doi.org/10.1016/j.transproceed.2013.08.079

11. Keller S, Konig AK, Marme F, Runz S, Wolterink S, Koensgen D, Mustea A, Sehouli J, Altevogt P (2009) Systemic presence and tumor-growth promoting effect of ovarian carcinoma released exosomes. Cancer Lett 278:73-81. https://doi.org/10.1016/j.canlet.2008.12.028

12. Sharma S, Gillespie BM, Palanisamy V, Gimzewski JK (2011) Quantitative nano structural and single-molecule force spectroscopy biomolecular analysis of human-saliva-derived exosomes. Langmuir 27:14394-14400

13. Besra SK, Harsh V, Kumar H, Mallik J, Sahay CB, Kumar A (2020) Intracranial meningiomas: experience at a tertiary healthcare center in India. Int J Neuro Oncol 3(2):87-92. https://doi.org/ 10.4103/IJNO.IJNO_5_20

14. Ostrom QT, Gittleman H, Xu J et al (2016) CBTRUS statistical report: primary brain and other central nervous system tumors diagnosed in the United States in 2009-2013. Neuro Oncol 18(Suppl. 5):v1-v75. https://doi.org/10.1093/neuonc/now207

15. Hatch EE, Linet MS, Zhang J et al (2005) Reproductive and hormonal factors and risk of brain tumors in adult females. Int J Cancer 114(5):797-805. https://doi.org/10.1002/ijc.20776

16. Zada G, Başkaya MK, Shah MV (2017) Introduction: surgical management of skull base meningiomas. Neurosurg Focus. https:// doi.org/10.3171/2017.10.FocusVid.Intro

17. Cui GQ, Jiao AH, Xiu CM, Wang YB, Sun P, Zhang LM, LiActa XG (2014) Proteomic analysis of meningiomas. Acta Neurol Belg 114(3):187-194. https://doi.org/10.1007/s13760-013-0253-Z

18. Okamoto H, Li J, Vortmeyer AO, Jaffe H, Lee YS, Gläsker S, Sohn TS, Zeng W, Ikejiri B, Proescholdt MA, Mayer C, Weil RJ, Oldfield EH, Zhuang Z (2006) Comparative proteomic profiles of meningioma subtypes. Cancer Res 66:20. https://doi.org/10.1158/ 0008-5472.CAN-06-0955

19. Sharma S, Ray S, Moiyadi A, Sridhar E, Srivastava S (2014) Quantitative proteomic analysis of meningiomas for the identification of surrogate protein markers. Sci Rep 4:7140

20. Dunn J, Ferluga S, Sharma V, Futschik M, Hilton DA, Adams CL, Lasonder E, Hanemann CO (2019) Proteomic analysis discovers the differential expression of novel proteins and phosphoproteins in meningioma including NEK9, HK2 and SET and deregulation of RNA metabolism. EBioMedicine 40:7791. https://doi.org/10. 1016/j.ebiom.2018.12.048

21. Sharma S, Ray S, Mukherjee S, Moiyadi A, Sridhar E, Srivastava $S$ (2015) Multipronged quantitative proteomic analyses indicate modulation of various signal transduction pathways in human meningiomas. Proteomics 15:394-407. https://doi.org/10.1002/ pmic. 201400328

22. Mukherjee S, Biswas D, Gadre R, Jain P, Syed N, Stylianou J, Zeng Q, Mahadevan A, Sridhar E, Shetty P, Moiyadi A, Ball GR, Srivastava S (2020) Comprehending meningioma signaling cascades using multipronged proteomics approaches \& targeted validation of potential markers. Front Oncol 10:1600. https://doi. org/10.3389/fonc. 2020.01600

23. Saydam O, Senol O, Schaaij-Visser TB, Pham TV, Piersma SR, Stemmer-Rachamimov AO, Würdinger T, Peerdeman SM, Jimenez CR (2010) Comparative protein profiling reveals minichromosome maintenance (MCM) proteins as novel potential tumor markers for meningiomas. J Proteome Res 9(1):485-494. https:// doi.org/10.1021/pr900834h

24. Johnson MD, Woodard A, Kim P, Frexes-Steed M (2001) Evidence for mitogen-associated protein kinase activation and transduction of mitogenic signals by platelet-derived growth factor in human meningioma cells. J Neurosurg 94:293-300. https://doi. org/10.3171/jns.2001.94.2.0293

25. Mawrin C, Sasse T, Kirches E, Kropf S, Schneider T, Grimm $\mathrm{C}$ et al (2005) Different activation of mitogen-activated protein kinase and Akt signaling is associated with aggressive phenotype of human meningiomas. Clin Cancer Res 11:4074-4082. https:// doi.org/10.1158/1078-0432.CCR-04-2550

26. Zhou K, Wang G, Wang Y, Jin H, Yang S, Liu C (2010) The potential involvement of E-cadherin and beta-catenins in meningioma. PLoS ONE 5:e11231. https://doi.org/10.1371/journal. pone. 0011231

27. Johnson M, Toms S (2005) Mitogenic signal transduction pathways in meningiomas: novel targets for meningioma chemotherapy? J Neuropathol Exp Neurol 64:1029-1036. https://doi.org/10. 1097/01.jnen.0000189834.63951.81

28. Johnson MD, Horiba M, Arteaga C (1994) The epidermal growth factor receptor is associated with phospholipase $\mathrm{C} \mathrm{g}$ in meningiomas. Human Pathol 25:146-153

29. Baia GS, Stifani S, Kimura ET, McDermott MW, Pieper RO, Lal A (2008) Notch activation is associated with tetraploidy and enhanced chromosomal instability in meningiomas. Neoplasia 10:604-612. https://doi.org/10.1593/neo.08356

30. Zeng Q, Li S, Chepeha DB, Giordano TJ, Li J, Zhang $\mathrm{H}$ et al (2005) Crosstalk between tumor and endothelial cells promotes tumor angiogenesis by MAPK activation of Notch signaling. Cancer Cell 8:13-23. https://doi.org/10.1016/j.ccr.2005.06.004

31. Laurendeau I, Ferrer M, Garrido D, D'Haene N, Ciavarelli P, Basso A et al (2010) Gene expression profiling of the hedgehog signaling pathway in human meningiomas. Mol Med 16:262-270. https://doi.org/10.2119/molmed.2010.00005

32. Mavila N, Thundimadathil J (2019) The emerging roles of cancer stem cells and wnt/beta-catenin signaling in hepatoblastoma. Cancers 11:1406. https://doi.org/10.3390/cancers11101406

33. Johnson MD, Okediji E, Woodard A (2004) Transforming growth factor-b effects on meningioma cell proliferation and signal transduction pathways. J Neuro-Oncol 66:9-16. https://doi.org/10. 1023/b:neon.0000013461.35120.8a

34. Domingues P, Tablas MG, Otero A, Pascual D, Ruiz L, Miranda D, Sousa P, Gonçalves JM, Lopes MC, Orfao A, Tabernero MD (2015) Genetic/molecular alterations of meningiomas and the signaling pathways targeted. Oncotarget 6(13):10671-10688. https://doi.org/10.18632/oncotarget.3870 
35. Kwon CH, Park HJ, Lee JR, Kim HK, Jeon TY, Jo HJ, Kim DH, Kim GH, Park DY (2014) Serpin peptidase inhibitor clade A member 1 is a biomarker of poor prognosis in gastric cancer. $\mathrm{Br}$ J Cancer 11:1993-2002. https://doi.org/10.1038/bjc.2014.490

36. Abbritti RV, Polito F, Cucinotta M, Giudice CL, Caffo M, Tomasello C, Germanò A, Aguennouz M (2016) Meningiomas and proteomics: focus on new potential biomarkers and molecular pathways. Cancer Genom Proteom 13:369-380

37. Bouwens TA, Trouw LA, Veerhuis R, Dirven CM, Lamfers ML, Al-Khawaja H (2015) Complement activation in glioblastoma multiforme pathophysiology: evidence from serum levels and presence of complement activation products in tumor tissue. J Neuroimmunol 278:271-276. https://doi.org/10.1016/j.jneur oim.2014.11.016

38. Hashemi ML, Pooladi M, Razi Abad SK (2014) Apolipoprotein A1 and albumin in malignant astrocytoma brain tumor. J Cancer Res Ther 10(1):107-111

39. Sharma S, Ray S, Mukherje S, Moiyadi A, Sridhar E, Srivastava $S$ (2015) Multipronged quantitative proteomic analyses indicate modulation of various signal transduction pathways in human meningiomas. Proteomics 15:394-407

40. Bello L, Zhang J, Nikas DC, Strasser JF et al (2000) Alpha (v) beta3 and alpha (v) beta5 integrin expression in meningiomas. Neurosurgery 47:1185-1195. https://doi.org/10.1097/00006 123-200011000-00035

41. Bergoglio MT, Gomez-Balaguer M, Almonacid FE, Hurtado MF, Hernandez-Mijares A (2013) Symptomatic meningioma induced by cross-sex hormone treatment in a maleto-female transsexual. Endocrinol Nutr 60:264-267

42. Bajetto A, Barbieri F, Pattarozzi A, Dorcaratto A et al (2007) CXCR4 and SDF1 expression in human meningiomas: a proliferative role in tumoral meningothelial cells in vitro. Neuro Oncol 9:3-11. https://doi.org/10.1215/15228517-2006-023

43. Caltabiano R, Barbagallo GM, Castaing M, Cassenti A et al (2013) Prognostic value of EGFR expression in de novo and progressed atypical and anaplastic meningiomas: an immunohistochemical and fluorescence in situ hybridization pilot study. J Neurosurg Sci 57:139-151

44. Sabbatini M, Comi C, Chiocchetti A, Piffanelli V et al (2011) Signals of apoptotic pathways in several types of meningioma. Pathol Oncol Res 17:51-59

45. Johnson MD, O'Connell M, Pilcher W (2011) Lopinavir inhibits meningioma cell proliferation by Akt independent mechanism. J Neurooncol 101:441-448. https://doi.org/10.1007/ s11060-010-0281-y

46. Cheng G, Zhang L, Lv W, Dong C, Wang Y, Zhang J (2015) Overexpression of cyclin D1 in meningioma is associated with malignancy grade and causes abnormalities in apoptosis, invasion and cell cycle progression. Med Oncol (Northwood Lond Engl). 32:439. https://doi.org/10.1007/s12032-014-0439-0

47. Pachow D, Wick W, Gutmann DH, Mawrin C (2015) The mTOR signaling pathway as a treatment target for intracranial neoplasms. Neuro Oncol 17:189-199. https://doi.org/10.1093/ neuonc/nou 164

48. Huang H (2018) Matrix metalloproteinase-9 (MMP-9) as a cancer biomarker and MMP-9 biosensors: recent advances. Sensors (Basel Switzerland) 18:3249

49. Aggarwal BB, Sethi G, Ahn KS, Sandur SK, Pandey MK, Kunnumakkara AB et al (2006) Targeting signal-transducerand-activator-of-transcription-3 for prevention and therapy of cancer: modern target but ancient solution. Ann N Y Acad Sci 1091:151-169. https://doi.org/10.1196/annals.1378.063

50. Rajendran L, Bali J, Barr MM et al (2014) Emerging roles of extracellular vesicles in the nervous system. J Neurosci 34:15482-15489. https://doi.org/10.1523/JNEUROSCI.3258-14
51. Thakur BK, Zhang H, Becker A et al (2014) Double-stranded DNA in exosomes: a novel biomarker in cancer detection. Cell Res 24:766-769

52. Kahlert C, Melo SA, Protopopov A et al (2014) Identification of double-stranded genomic DNA spanning all chromosomes with mutated KRAS and p53 DNA in the serum exosomes of patients with pancreatic cancer. J Biol Chem 289:3869-3875. https://doi. org/10.1074/jbc.C113.532267

53. Colombo M, Raposo G, Thery C (2014) Biogenesis, secretion, and intercellular interactions of exosomes and other extracellular vesicles. Annu Rev Cell Dev Biol 30:255-289. https://doi.org/10. 1146/annurev-cellbio-101512-122326

54. Thery C, Ostrowski M, Segura E (2009) Membrane vesicles as conveyors of immune responses. Nat Rev Immunol 9:581-593

55. Li B, Antonyak MA, Zhang J, Cerione RA (2012) RhoA triggers a specific signaling pathway that generates transforming microvesicles in cancer cells. Oncogene 31:4740-4749. https://doi.org/10. 1038/onc.2011.636

56. Di Vizio D, Kim J, Hager MH et al (2009) Oncosome formation in prostate cancer: association with a region of frequent chromosomal deletion in metastatic disease. Cancer Res 69:5601-5609. https://doi.org/10.1158/0008-5472.CAN-08-3860

57. Gyorgy B, Szabo TG, Pasztoi M et al (2011) Membrane vesicles, current state-of-the-art: emerging role of extracellular vesicles. Cell Mol Life Sci 68:2667-2688. https://doi.org/10.1007/ s00018-011-0689-3

58. Fruhbeis C, Frohlich D, Kuo WP et al (2013) Neurotransmitter triggered transfer of exosomes mediates oligodendrocyte-neuron communication. PLoS Biol 11:e1001604. https://doi.org/10.1371/ journal.pbio. 1001604

59. Mathai RA, Vidya RVS, Reddy BS, Thomas L, Udupa K, Kolesar J, Rao M (2019) Potential utility of liquid biopsy as a diagnostic and prognostic tool for the assessment of solid tumors: implications in the precision oncology. J Clin Med 8(3):373. https://doi. org $/ 10.3390 / \mathrm{jcm} 8030373$

60. Domínguez-Vigil IG, Moreno-Martínez AK, Wang JY, Roehrl MH, Barrera-Saldaña HA (2018) The dawn of the liquid biopsy in the fight against cancer. Oncotarget 9(2):2912-2922. https:// doi.org/10.18632/oncotarget.23131

61. Pasini L, Ulivi P (2019) Liquid biopsy for the detection of resistance mechanisms in NSCLC: comparison of different blood biomarkers. J Clin Med 8(7):998. https://doi.org/10.3390/jcm80 70998

62. Mathieu M, Martin-Jaular L, Lavieu G, Thery C (2019) Specificities of secretion and uptake of exosomes and other extracellular vesicles for cell-to-cell communication. Nat Cell Biol 21:9-17. https://doi.org/10.1038/s41556-018-0250-9

63. Macias M et al (2018) Liquid biopsy: from basic research to clinical practice. Adv Clin Chem 83:73-119. https://doi.org/10.1016/ bs.acc.2017.10.003

64. Sun B et al (2019) Circulating exosomal CPNE3 as a diagnostic and prognostic biomarker for colorectal cancer. J Cell Physiol 234:1416-1425. https://doi.org/10.1002/jcp.26936

65. Xu R, Greening DW, Zhu H-J, Takahashi N, Simpson RJ (2016) Extracellular vesicle isolation and characterization: toward clinical application. J Clin Investig 126:1152-1162. https://doi.org/10. 1172/JCI81129

66. Tannetta D, Masliukaite I, Vatish M, Redman C, Sargent I (2017) Update of syncytiotrophoblast derived extracellular vesicles in normal pregnancy and preeclampsia. J Reprod Immunol 119:98106. https://doi.org/10.1016/j.jri.2016.08.008

67. Hoshino A et al (2015) Tumour exosome integrins determine organotropic metastasis. Nature 527:329-335. https://doi.org/10. 1038/nature 15756

68. Théry C, Amigorena S, Raposo G, Clayton A (2006) Isolation and characterization of exosomes from cell culture supernatants and 
biological fluids. Curr Protoc Cell Biol. https://doi.org/10.1002/ 0471143030.cb0322s30

69. Castellanos-Rizaldos E et al (2018) Exosome-based detection of EGFR T790M in plasma from non-small cell lung cancer patients. Clin Cancer Res 24:2944-2950. https://doi.org/10.1158/10780432.CCR-17-3369

70. Sandfeld-Paulsen B et al (2016) Exosomal proteins as prognostic biomarkers in non-small cell lung cancer. Mol Ontol 10:15951602. https://doi.org/10.1016/j.molonc.2016.10.003

71. Chen IH et al (2017) Phosphoproteins in extracellular vesicles as candidate markers for breast cancer. Proc Natl Acad Sci USA 114:3175-3180. https://doi.org/10.1073/pnas.1618088114

72. Street JM, Koritzinsky EH, Glispie DM, Star RA, Yuen PS (2017) Urine exosomes: an emerging trove of biomarkers. Adv Clin Chem 78:103-122. https://doi.org/10.1016/bs.acc.2016.07.003

73. Raimondo $\mathrm{F}$ et al (2013) Differential protein profiling of renal cell carcinoma urinary exosomes. Mol Biosyst 9:1220-1233. https:// doi.org/10.1039/c3mb25582d

74. Melo SA et al (2015) Glypican-1 identifies cancer exosomes and detects early pancreatic cancer. Nature 523:177-182. https://doi. org/10.1038/nature14581

75. Smalley DM, Sheman NE, Nelson K, Theodorescu D (2008) Isolation and identification of potential urinary microparticle biomarkers of bladder cancer. J Proteome Res 7:2088-2096. https://doi. org/10.1021/pr700775x

76. Rupp AK et al (2011) Loss of EpCAM expression in breast cancer derived serum exosomes: role of proteolytic cleavage. Gynecol Oncol 122:437-446. https://doi.org/10.1016/j.ygyno.2011.04.035

77. Sharma $S$ et al (2017) Tumor-derived exosomes in ovarian cancerliquid biopsies for early detection and realtime monitoring of cancer progression. Oncotarget 8:104687-104703. https://doi.org/10. 18632/oncotarget.22191

78. Khan $\mathrm{S}$ et al (2012) Plasma-derived exosomal survivin, a plausible biomarker for early detection of prostate cancer. PLoS ONE 7:e46737. https://doi.org/10.1371/journal.pone.0046737

79. Peinado $\mathrm{H}$ et al (2012) Melanoma exosomes educate bone marrow progenitor cells toward a prometastatic phenotype through MET. Nat Med 18:883-891. https://doi.org/10.1038/nm.2753

80. Maji S et al (2017) Exosomal annexin II promotes angiogenesis and breast cancer metastasis. Mol Cancer Res 15:93-105. https:// doi.org/10.1158/1541-7786.MCR-16-0163

81. Tiedemann $\mathrm{K}$ et al (2019) Exosomal release of L-plastin by breast cancer cells facilitates metastatic bone osteolysis. Transl Oncol 12:462-474. https://doi.org/10.1016/j.tranon.2018.11.014

82. Bijnsdorp IV et al (2013) Exosomal ITGA3 interferes with non-cancerous prostate cell functions and is increased in urine exosomes of metastatic prostate cancer patients. J Extracell Vesicles 2:1-10. https://doi.org/10.3402/jev.v2i0.22097

83. Theodoraki MN, Yerneni SS, Hoffmann TK, Gooding WE, Whiteside TL (2018) Clinical significance of PD-L1 (+) exosomes in plasma of head and neck cancer patients. Clin Cancer Res 24:896-905. https://doi.org/10.1158/1078-0432.CCR-17-2664
84. Li C et al (2019) Clinical significance of PD-L1 expression in serum-derived exosomes in NSCLC patients. J Transl Med 17:355. https://doi.org/10.1186/s12967-019-2101-2

85. Lux A, Kahlert C, Grützmann R, Pilarsky C (2019) c-Met and PD-L1 on circulating exosomes as diagnostic and prognostic markers for pancreatic cancer. Int J Mol Sci 20:3305. https://doi. org/10.3390/ijms20133305

86. Mashouri L et al (2019) Exosomes: composition, biogenesis, and mechanisms in cancer metastasis and drug resistance. Mol Cancer 18:75. https://doi.org/10.1186/s12943-019-0991-5

87. Cecilia L (2015) Exosomes in diagnostic and therapeutic applications: biomarker, vaccine and RNA interference delivery vehicle. Expert Opin Biol Ther 1:103-117. https://doi.org/10.1517/14712 598.2015.977250

88. Prabhakar S, Taherian M, Gianni D, Conlon TJ, Fulci G, Brockmann J, Stemmer-Rachamimov A, Esteves MS, Breakefield XO, Brenner GJ (2013) Regression of schwannomas induced by adenoassociated virus-mediated delivery of caspase-1. Hum Gene Ther 24(2):152-162. https://doi.org/10.1089/hum.2012.094

89. Aspe JR, Osterman CJD, Jutzy JMS, Deshields S, Whang S, Wall NR (2014) Enhancement of gemcitabine sensitivity in pancreatic adenocarcinoma by novel exosome-mediated delivery of the survivin-T34A mutant. J Extracell Vesicles 17:3. https://doi.org/ 10.3402/jev.v3.23244

90. Hong S, Gao F, Sha Fu, Wang Y, Fang W, Huang Y, Zhang L (2018) Concomitant genetic alterations with response to treatment and epidermal growth factor receptor tyrosine kinase inhibitors in patients with EGFR-mutant advanced non-small cell lung cancer. JAMA Oncol 4(5):739-742. https://doi.org/10.1001/jamaoncol. 2018.0049

91. Cho E, Nam G-H, Hong Y, Kim YK, Kim D-H, Yang Y, Kim I-S (2018) Comparison of exosomes and ferritin protein nanocages for the delivery of membrane protein therapeutics. J Control Release 10(279):326-335. https://doi.org/10.1016/j.jconrel.2018.04.037

92. Haney MJ, Klyachko NL, Zhao Y, Gupta R, Plotnikova EG, He Z, Patel T, Piroyan A, Sokolsky M, Kabanov AV, Batrakova EV (2015) Exosomes as drug delivery vehicles for Parkinson's disease therapy. J Controll Release 207:18-30

93. Naseri M, Bozorgmehr M, Zöller M, Pirmardan ER, Madjd Z (2020) Tumor-derived exosomes: the next generation of promising cell-free vaccines in cancer immunotherapy. Oncoimmunology 9(1):1779991. https://doi.org/10.1080/2162402X.2020.1779991

94. Yan W, Jiang S (2020) Immune cell-derived exosomes in the cancer-immunity cycle trends. Cancer 6(6):506-517. https://doi. org/10.1016/j.trecan.2020.02.013

Publisher's Note Springer Nature remains neutral with regard to jurisdictional claims in published maps and institutional affiliations. 